\title{
The Importance of English Phrasal Verbs Use in the Business Writing-A Qualitative Analysis of Perceptions of Non-native Business Students in Pakistan
}

\author{
Ms. Nayyab Mufti Zohaib \\ Bahria University (BULC) \\ Dr. Summaira Sarfraz \\ National University of Computer and Emerging Sciences Pakistan
}

\begin{abstract}
The study aims to analyze the perception of students about the importance of phrasal verbs (PVs) in the academic writing and explore their reasons behind avoidance of PVs in their writings. Phrasal verbs are comprised of a verb + preposition or verb + adverb combination. The most common English phrasal verbs are as important as other more frequent phrases during the process of English learning (Chen, 2007). In the context of Pakistan, students use phrasal verbs but are unaware of its importance in their writing composition due to lack of its teaching at primary and secondary level. Due to the same reason they avoid them in their writings. The study has followed qualitative approach to understand student's perception about the importance of phrasal verbs in writing composition after giving them practice lessons on phrasal verbs for a month. Participants of the study are 50 undergraduate students enrolled in the Management Sciences degree program. The data is collected from focus group discussions and analyzed through the transcription of emerging themes. The results showed positive perception of students regarding use of phrasal verbs in their writing, yet they feel hesitant in using them without teacher guidance due to their lack of practice. Phrasal verbs should be included in syllabus as students are using them unknowingly and incorrectly that is adversely affecting their writing skills.
\end{abstract}

Keywords: Phrasal verbs (PVs), perception of students, writing composition

DOI: $10.7176 / \mathrm{JEP} / 10-6-01$

\section{Introduction}

Phrasal verbs are important component of writing. It is a phrase comprises of a verb+ preposition or verb+adverb combination. Phrasal verbs cause ambiguity for L2 learners (Koprowski, 2005) (Junyu, Chen, 2007). It is because they covey different meanings apart from the meaning of its separate parts in different contexts (Junyu, 2007). The importance of Phrasal verbs in oral and written composition for developing native like English skills is unquestionable (Bronshteyn, 2015). Phrasal verbs are overlooked in language textbooks (Mukundan and Zarifi, 2012). This implies that phrasal verbs are avoided by L2 learners due to their ignorance and passive learning for writing. It is important to examine problems that L2 learners face in learning and using phrasal verbs in their written texts and how effective teaching approach can reduce these problems by making students aware of its usability in English texts. Thornton and Houser (2005) stated that: "The teacher must make difficult choices about how to use that limited class time to promote language learning". Many researches further pointed out that non-native speakers do not feel comfortable with use of phrasal verbs and thus avoid them while writing or speaking in the foreign language (Liao \& Fukuya, 2003). White (2012) explained "for ESL learners it is often difficult to acquire PVs because they are unpredictable, frequent and polysemous" (Junyu, 2012). These verbs are unpredictable for learners because they give literal as well as idiomatic meanings in different contexts. "They are also polysemous, because one phrasal verbs can be used in various meaningful ways, thus give different meaning in different contexts" (Junyu, 2012).

Indeed, the learning of recognition, comprehension, and actively use of phrasal verbs is an important part of learning English as a second/foreign language. Importance of Phrasal verbs is predominant in written and spoken English (Burke, 2002). Learners came across its use in diverse contexts, thus it is important for them to learn its use and meanings in order to communicate efficiently (Ostyn, 2003). Learners encounter discomfiture as a result of misunderstanding and misusing of phrasal verb (Zarifi, 2014). The main challenge, as pointed out by Karim (2015) and Ghabanchi (2012) in their researches seemed to originate from the prevalent misunderstanding among learners about meanings of phrasal verbs. They have difficult or different meanings that are not transparent to the second/foreign language learners. The American Heritage Dictionary of Phrasal Verbs (2005) stated that English learners might face a lot of issues with phrasal verbs as they are a combination of two English particles; verb and a proposition or verb and adverbial those give figurative meanings not known or predictable to the second language learner. Dagut and Laufer (1985) stated that "learners of English avoid using phrasal verbs that are absent in their native language because "learners avoid using what they do not properly understand ". Zarifi and Mukundan (2014) study on teaching of phrasal verbs concluded that ESL learners were able to 
learn phrasal verbs but they usually used unnatural form of phrasal verbs or create their own forms while using them. It is the duty of teachers to provide them with appropriate materials and activities that can teach them right form and use of phrasal verbs in different contexts.Hence, phrasal verbs are considered as an important grammatical component in learning English. Plethora of researches have been conducted to identify difficulties faced by second language learners yet there is less focus on its teaching in language classrooms and even its inclusion in language textbooks at universities. It has been identified through number of researches that use of phrasal verbs in ESL textbooks is limited. Moreover there are many researches on pedagogies for improvement of phrasal verbs but their results are not incorporated into classroom activities and English Language Teaching (ELT) materials (Mukundan, 2015).

Since English is an official language of Pakistan, fluency in English often results in gaining lucrative jobs and greater access to higher education. In language learning, English phrasal verbs play rather an indispensable role in communication particularly in oral and written forms. The most common English phrasal verbs are as important as other more frequent phrases during the process of English learning (Chen, 2007). Without sufficient phrasal verbs, one may not develop native like fluency in English language (Fauziati, 2005).

\subsection{Statement of the problem}

Since in Pakistan phrasal verbs are not included as part of syllabus in language classrooms, students had knowledge of common phrasal verbs but were not aware of their importance in the writing composition .This implicated that students were not avoiding phrasal verbs knowledgeably. Their ignorance and insufficient knowledge were culprits for the avoidance of phrasal verbs in their written texts.

\subsection{Objectives of the study}

- To analyze the perception of students about use of phrasal verbs in English writing composition of Pakistani undergraduate students.

- $\quad$ To explore the avoidance of phrasal verbs by the Pakistani students in their writing

\section{Literature Review}

It is well researched that ESL learners create unnatural forms while using phrasal verbs in their writing as well as communicative skills. Moreover, learning of Phrasal verbs creates various problems for second language learners; they convey meanings that are not transparent after the combination of its individual components. Phrasal verbs also have alienated property for many languages. Such as there are various languages to which phrasal verbs are quite alien such as Germanic languages (Murcia\& Freeman, 1999) as well as non-German languages like Malay. So when such students expose to PVs it not only creates syntactic diversity but also semantic complexity, because Phrasal verbs do not have only one form but of various compositional uses such as literal, aspectual and idiomatic. Such learners, due to non-familiarity with phrasal verbs feel comfortable with literal verbs but usually avoid using difficult idiomatic phrases. Literal forms are usually easy to learn as it indicates the literal meanings but when it comes to idiomatic forms such as (ran into or give up), need attention to acquire use competencies.

According to Bronshteyn and Gustafson (2015), ESL learners usually prefer to avoid PVs and face difficulty when they attempt to use them. Authors presented critical review of various researches and assessed different literatures related to pedagogical strategies that can support L2 students in the learning of PVs. It highlighted mastery problem and avoidance by reviewing studies like of Liao and Fukuya (2004) study, that concluded the avoidance is mainly due to the influence of native language, when native language do not have PVs, their speakers tend to avoid it in their second languages, specifically learning of idiomatic PVs such as the speakers of Hebrew. Likewise it mentioned (Dagut \& Laufer, 1985). Hulstijn and Marchena (1989) study on Dutch learners of English. Dutch have PVs in their native languages thus they did not categorilearningy avoid them yet try not to use idiomatic PVs. Strangely, PVs that had a similar counterpart in the L1 were avoided. If language proficiency will be focused by teachers, then avoidance or other problems can be reduced. Thus, it is directive for language teachers to adopt strategies to develop proficiency in use of PVs among ESL.In the next session, Bronshteyn and Gustafson (2015) elaborated the role of teacher's knowledge of PVs and their effectiveness in delivering or imparting that knowledge to students. Teachers need to develop syntactic awareness of PVs to design effective pedagogical strategies. According to Bronshteyn and Gustafson (2015), three innovative strategies are worthwhile for teaching PVs, researched by Nassaji and Tian (2010), collaborative work assignments rather than individual task, White (2012) who introduced a 5-step methodology of learning PVs through drawings, consisting of students reorienting to the meanings, gather PVs, discussing the meaning, small group discussions, and then sharing their drawings as by drawing, students could symbolize the meanings and present it to classmates, and of Oe and Alam (2013), that used pictures to teach PVs to students in an interactive manner. The results of all three suggested techniques were positive in optimizing students mental capabilities in learning Phrasal Verbs. 
As mentioned above, English Second Language (ESL) learners mostly face difficulties in acquiring and mastering of Phrasal verbs (PVs) and thus using it effectively in their speaking and writing. This suggests for teaching strategies that focus more on understanding of the grammatical pattern of such verbs for ESL learners instead of learning through memorization. Moreover, text books also play an important role in assisting teacher's efforts in this regard, but it is to note that textbooks can also confuse students and can create difficulties for teachers if will entirely ignore the compositional difficulties of phrasal verbs. Usually in text books phrasal verbs are given but without any description of learnable patterns or even create patterns of the wrong kind (Side 1990). Many researchers are of the opinion that further help with ELT material can aid students in reducing the difficulties in using these combinations of phrasal verbs.Due to all these problems, students in ESL context usually start avoiding PV use in their writing and communicative skills. In various studies, it was found that second language learners often avoid phrasal verbs and there could be various factors contributing to the avoidance of English phrasal verbs by non-native learners. According to Junyu \& Chen (2007), such factors include institutional factors, societal factors, teacher and learner factors as well as ineffective curriculum documents. Mainly, the lack of foreign language environment is likely to be the most important factor to cause the problem of the avoidance of English phrasal verbs by non-native learners. They get fewer opportunities to communicate in the language and also practice in reading, writing and listening of the foreign language. Moreover, they get less chance to practice the learned aspects outside the classroom because classroom English and everyday English are more often employ different discourses. Thus lack of practice and individually spaced repetition, that is the opposite of massed repetition, on topics related to everyday life is likely to result in ineffective or less confident communication. Even after the relevant language knowledge has been taught in the classroom by teachers (Nation, 2001).

Wild (2010) mentioned many reasons of avoidance and Nonetheless, among one of the important reasons for avoiding the use of phrasal verbs is the exposition to the English language. Another reason for avoidance of the phrasal verbs is the lack of required educational and teaching resources for communicating with each other. With the passage of time, many languages are trying to adopt English language for example the Chinese language is becoming similar to that of the English language with the composition of some similar words in both the languages (Junyu, 2007). In the current era, it is better to use phrasal verbs as part of teaching with the help of media materials as it is prominently use by native speakers of English language (Montazeri, 2013).

\section{Methodology}

Researchers used qualitative approach to collect data.

\subsection{Participants}

The sample size for quantitative study was comprised of 50 participants. All of the participants in the present study were from same academic backgrounds; while some held the degrees of F.A. or F.Sc., others had completed their A levels and had also taken English reading and writing proficiency course in their first semester.

\subsection{Method and procedures:}

The qualitative approach in the study involved focus group discussions of the students to get their perception about the importance of use of phrasal verbs in their writing and reasons of its avoidance. Focus group discussions are gaining rapid popularity in the field of education as they are an effective source of providing information on people's views on specific topics (Freitas et al., 1998) (Cohen D, Crabtree B., 2006). The data was collected from the three Focus group discussions and the dominant themes emerging from the transcriptions were analyzed (Chioncel, et. al., 2003). Three focus group discussions were conducted to maintain internal consistency and saturation of results (Marczale \& Sewell, 2010).

\section{Results and Analysis}

Themes were developed from the transcribed Focus group discussions. (See Appendix B) Participants showed positive response towards LEARNING for teaching phrasal verbs in one month intervention.

\subsection{Lack of phrasal verb awareness}

This theme emerged in response to the question Were you using phrasal verbs in your texts before learning sessions? The answers of majority participants declared lack of awareness of phrasal verbs. They were from Matric and O-levels background and had not studied phrasal verbs in their primary schools.

\section{P.2: "For me, I haven't studied phrasal verbs before ever..."}

P.6: "We didn't study phrasal verbs in O levels."

Although one student was familiar with phrasal verbs but it was just a general concept and not the actual use of verbs in sentences as all were not sure of its knowledge from their primary schools. 
P.5: "At school level we were never taught"

A.7: "We didn't as such, just once may be"

4.2 Willingness to use phrasal verbs

This theme emerged from the question Will you use phrasal verbs in writing your paragraphs after learning sessions? After learning sessions, participants had developed a positive perception about phrasal verbs as important part of writing. Although, few students expressed difficulty in using phrasal verbs in his writing, he still had positive views of learning from LEARNING sessions.

P.13: "No I will write in easy English"

According to most of the participants, phrasal verbs enhanced quality of their writing and improved their expression.

P.2: "Yes because it makes the writings efficient"

P.6: "Yes because it's good to use phrasal verb in writing"

P.7: "Yes it's a good practice and it makes a good image of the writer on the reader"

P.4: "Yes I will definitely use because it leaves the good impression of writing, overall” P.1: "Now I use phrasal verbs in different contexts because phrasal verbs makes our writing a formal and attractive"

\subsection{Assistance dependency}

This theme emerged in response to the questions Will you use phrasal verbs in writing even if it will not be marked by class teacher? Responses to these question presented an opposing view to their willingness for using phrasal verbs; as they were hesitant in using them because of fear of making mistakes, needing more time in order to think and use phrasal verbs in their writing.

P.3: "No I do not know if I can use them correctly"

P3: "Yes exactly, we fear of making mistakes"

The findings indicate that they need assistance in their use of phrasal verbs and more practice with teacher supervision. It is further affirmed by their responses

P.3: "Because time was short to think"

P7: "We taught in a month only"

This implies that although students were given practice in the one month, they still feel that they need supervision or assistance so as to avoid mistakes. Although they feel that learning session has improved their understanding and encourages them to use phrasal verbs independently in enhancing their writing ability.

Qualitative results showed that the students had little or no awareness of phrasal verbs as they were not taught at their primary and secondary levels. Learning sessions were helpful in creating positive understanding of phrasal verbs among participants. However, they still expressed the difficulty in using phrasal verbs without teacher's supervision due to lack of practice.

\section{Discussion}

Phrasal verbs have always been considered problematic for L2 learners as researched by a number of researchers on their learning and teaching problems. Karim (2015) elaborated the major issue of ESL learners in his study that they create unnatural forms of phrasal verbs while using phrasal verbs in their writing. Students were given phrasal verbs learning sessions for a month before getting their perceptions about the use of phrasal verbs in the writing composition. This was helpful in reducing avoidance behavior of students that they might develop due to their perception of difficulty about phrasal verbs. According to Bronshteyn and Gustafson (2015), English Second Language (ESL) learners usually prefer to avoid PVs because they face difficulty when they attempt to use them. Moreover ESL learners also avoid phrasal verbs due to difficulties in acquiring and mastering of Phrasal verbs (PVs) and thus using it effectively in their speaking and writing compositions Karim (2015) and Ghabanchi (2012).

Students expressed their hesitation even they were developed positive perceptions about phrasal verbs. It meant that students need motivation to use such verbs apart of exposure and awareness. They should be encouraged to use verbs without any assistance or fear of making mistakes. It should be considered that undergraduate students in Pakistan have low English language proficiency, they mostly make structure and grammatical errors while writing. This might be one factor of their avoidance of phrasal verbs. This was further elucidated by reviewing responses of participants in Focus group discussions, students made various grammatical errors while sharing their opinions. English learners in Pakistan used to practice translation technique from native to second language at their primary and secondary levels, thus make a lot of errors in using English in oral as well as written productions. Ghabanchi (2012) in his study found that Asian students "do not prefer to use phrasal verbs in their writings because of the difficulty they face in determining its meaning and use in that context". The data from qualitative study led to further elaboration on the same point, according to the responses of students', they did not prefer to use phrasal verbs in their sentences frequently "because they were confused if they can use them correctly to deliver their actual thoughts". Although, they had learned meanings 
and use of various phrasal verbs in different contexts with the help of learning sessions. They needed regular practice and motivation to use phrasal verbs frequently and comfortably.

The results indicated towards the acknowledgement of students about phrasal verbs as important component to enhance English proficiency. Students admitted by themselves about the significance of phrasal verbs in increasing quality of their written texts. (P.2: "Yes because it makes the writings efficient"). (P.6: "Yes because it's good to use phrasal verb in writing") (P.7:"Yes it's a good practice and it makes a good image of the writer on the reader") (P.4: "Yes I will definitely use because it leaves the good impression of writing, overall"). (P.1: "Ma'am, now I use phrasal verbs in different contexts because phrasal verbs makes our writing a formal and attractive")

However, they did not use phrasal verbs in their writing. It is mainly due to their assistance dependence as found in theme developed by responses of participants in Focus group discussions. (P.3: "No I do not know if I can use them correctly") (P3:"Yes exactly, we fear of making mistakes").

\section{Conclusion}

The results showed that the students got familiarity with phrasal verbs as the important component of English writing. Students were unaware of phrasal verbs in terms of syntactic use and not taught before. Although learning session had improved their understanding and encouraged them to use phrasal verbs as they found it useful in enhancing their writing ability. Teaching of phrasal verbs sessions were also helpful in increasing learning motivation of students. However, they did not prefer to use phrasal verbs in their writing. It is mainly due to their assistance dependence as found in theme developed by responses of participants in Focus group discussions. When students were asked of reason behind their less use of phrasal verbs in paragraph writing, majority mentioned "their fear about misusing them or choosing wrong particle" As also stated by Sojholm (1995) that, "the multiplicity and the complexity would make phrasal verbs as unattractive components to L2 learners of phrasal verbs (Jarvis and Pavelenco, 2008)

\section{References}

Bronshteyn, Karen Cathcart and Gustafson, Tom (2015) "The Acquisition of Phrasal Verbs in L2 English: A Literature Review," Linguistic Portfolios: Vol. 4 , Article 8.

Campbell DT, Stanley JC (1963). Experimental and quasi-experimental designs for research. Chicago: Rand McNally \& Company

Celce-Murcia, M., \& Larsen-Freeman, D. (1999). The grammar book: An ESL/EFL teacher's course. Boston: H \& H Publishers.

Creswell, J. W. (2007). Designing and conducting mixed methods research. SAGE.

Dagut, M., \& Laufer, B. (1985). Avoidance of phrasal verbs - A case for contrastive analysis. Studies in Second Language Acquisition, 7(1), 73-79.

Golafshani, N. (2003). Understanding reliability and validity in qualitative research. The Qualitative Report, $8(4), 597-606$.

Dagut, M., \& Laufer, B. (1985). Avoidance of Phrasal Verbs - a Case for Contrastive Analysis. Studies in Second Language Acquisition, 7(1), 73-79.

Darwin, C. M., \& Gray, L. S. (1999). Going after the Phrasal Verb: An Alternative Approach to Classification.

Hussein Muhammadi Farsani, A. M. (2012, March). Mnemonic Effectiveness of CL-motivated Pictureelucidation Tasks in Foreign Learners' Acquisition of English Phrasal Verbs. Theory and Practice in Language Studies, 2(3), 498-509.

Irshad, S., \& Mamuna, G. (2011). Effectiveness of computer assisted language learning (LEARNING) in Pakistani ESL perspective: A quasi experimental study. Paper published in Proceedings of the 3rd International Conference of Teaching and Learning (ICTL 2011). INTI International University, Malaysia

Junyu, Chen. (2007). On how to solve the problem of the avoidance of phrasal verbs in the Chinese context. International Education Journal, 8(2), 348-353.

Karen Cathcart Bronshteyn, T. G. (2015). The Acquisition of Phrasal Verbs in L2 English: A Literature Review. Linguistic Portfolios, 4.

Jahedi, M., \& Mukundan, J. (2015). A Review on Studies of Phrasal Verb Constructions in ESL Context. Advances in Language and Literary Studies, 6(1), 157-162. Retrieved from http://journals.aiac.org.au/index.php/alls/article/view/687

Shahzad Karim, D.-e.-S. (2015). Avoidance of English Phrasal Verbs:. ELF Annual Research Journal, 125-144.

White, B. J. (2012). A Conceptual Approach to the Instruction of Phrasal Verbs. The modern language journal, 96(3), 419-438.

Wild, C. (2010). Attitudes towards English use in the late modern period: the case of phrasal verbs. Glasgow Theses Service, 2264.

Zargham Ghabanchi, E. G. (2012). Avoidance of Phrasal Verbs in Learner English:A Study of Iranian Students. 
World Journal of English Language, 2(2), 43.

Zarifi, A., \& Mukundan, J. (2012). Phrasal verbs in Malaysian ESL textbooks. English Language Teaching, 5(5), 9-18.

Zarifi, A., \& Mukundan, J. (2014a). Creativity and unnaturalness in the use of phrasal verbs in ESL learner language. 3L: The Southeast Asian Journal of English Language Studies, 20(3), 51- 62. 